\title{
A Globally Integrated Supply Chain Delivery Quality Strategy: Transformation Insights at the Nokia Devices Unit
}

\author{
Anne-Maarit Majanoja ${ }^{*}$, Michael C. Loney², Björn Wörlund³, Linnéa Linko4, \\ Ville Leppänen ${ }^{1}$ \\ ${ }^{1}$ Department of Information Technology, University of Turku, Turku, Finland \\ ${ }^{2}$ Supply Chain Management, Fort Worth, Texas, USA \\ ${ }^{3}$ Insurance and Risk Management, Kauniainen, Finland \\ ${ }^{4}$ Turku Centre for Biotechnology, University of Turku, Turku, Finland \\ Email: ${ }^{*}$ anne-maarit.majanoja@outlook.com
}

Received 9 July 2014; revised 30 July 2014; accepted 10 August 2014

Copyright (C) 2014 by authors and Scientific Research Publishing Inc.

This work is licensed under the Creative Commons Attribution International License (CC BY).

http://creativecommons.org/licenses/by/4.0/

(c) (i) Open Access

\begin{abstract}
In recent years, it has become even more critical for companies to respond efficiently and timely to customers' expectations. Therefore, Delivery Quality (DQ) is critical in supply chain management. In this research, we focus on analyzing the impacts of the DQ strategy implementation, and the main forces of the DQ change management and DQ leadership. At Nokia, the effort to establish a new globally integrated DQ strategy to improve its trade customers' perception visibility was successful. The globally integrated DQ strategy, which combined product, logistics, and Marine transit insurance, was developed and implemented worldwide. Nokia had a contradictory approach by requiring all stakeholders, including external subcontractors and the insurance company, to use Nokia-owned processes and IT solutions. The identified key success factors were an efficient global DQ strategy, quality and customer-centric ideology, clear and efficient governance and leadership, clarity of ownership, global DQ practices, a total control of all trade customer claims, and DQ performance monitoring. These factors improved global DQ management. The practices can be adopted by other companies to further improve their supply chain DQ operations development.
\end{abstract}

\section{Keywords}

Delivery Quality, Insurance, Leadership, Customer Perception, Transformation

\footnotetext{
${ }^{*}$ Corresponding author.
}

How to cite this paper: Majanoja, A.-M., Loney, M.C., Wörlund, B., Linko, L. and Leppänen, V. (2014) A Globally Integrated Supply Chain Delivery Quality Strategy: Transformation Insights at the Nokia Devices Unit. American Journal of Industrial and Business Management, 4, 413-431. http://dx.doi.org/10.4236/ajibm.2014.48050 


\section{Introduction}

In the present global economy, every company must respond efficiently to customers' needs and expectations. Increased shareholder value is demanded continuously, and growth and profitability are basic expectations. Organizations are focused more on their core activities, fulfilling shareholders expectations, and cost saving targets rather than the customers' perception. Therefore, implementing a quality and customer-centric operation may require transformational change management activities. Delivery Quality (DQ) is critical in supply chain management. It is a distinctive factor for managing customers' quality perception. If the quality of the product is good, but the products are not fulfilling the agreements (such as: time, schedule, quantity, and condition), the total expected quality is not achieved.

Various kinds of delivery failures and complaints arise, such as damage, missing items, and unsatisfactory packaging. It is critical to understand customers' DQ perception. Successful DQ mode-of-operation adaptation and global level transformation can be challenging, unless the senior executives invest in building the needed capabilities and empowering the DQ leadership. Customers need to be encouraged to disclose DQ related non-conformances and companies must have rapid corrective actions to correct the realized non-conformances. Companies must listen, understand, and respect their customers' points of view. If the company does not have a clear knowledge of its DQ condition, the company may have an inaccurate supply chain quality impression. The lack of DQ knowledge and DQ management may prevent the company from conducting the needed corrective and preventive actions and change management activities properly to satisfy its customers. The core company must ensure that all entities in their entire supply chain are performing according to the same quality standards to ensure the entire system is consistently meeting or exceeding customer satisfaction requirements worldwide.

Companies' global level requirements and challenges raise questions about the needed DQ capabilities to successfully establish the needed quality and customer-centric DQ solutions and practices. However, far too little attention has been paid to global DQ operation implementation and change management. Companies' operational level activities are mainly company and field specific solutions, and these specific solutions cannot be easily adapted by other companies. We focus on global DQ management level activities and analyzing various DQ change management and leadership elements (Figure 1). In fact, the DQ management level activities are the driving forces to implement the planned changes into the operational level activities, practices, and working culture worldwide. Similarly, we introduce generalized DQ claims management aspects and a globally integrated DQ strategy that combines product, logistics and Marine transit insurance claims.

We used an action research method and the authors' knowledge and hands-on experience to present the drivers, constraints, actions, and identified DQ capabilities. We also present analysis findings of the global DQ management and leadership elements. To illustrate the importance of DQ operational environment elements and DQ management and leadership activities, we used instances and illustrations from telecommunication field and the case company (Nokia Devices) to explain the significance and practicalities of DQ. Our focus is on logistics and supply chains' DQ including product, logistics, and Marine transit insurance (insurance claims are limited only to Marine transit cargo claims). We examined intermediate (trade) customer DQ and all aspects up to "the point-of-sale" (POS), and excluded end-consumer purchases and all aspects after POS to consumers. Here, DQ

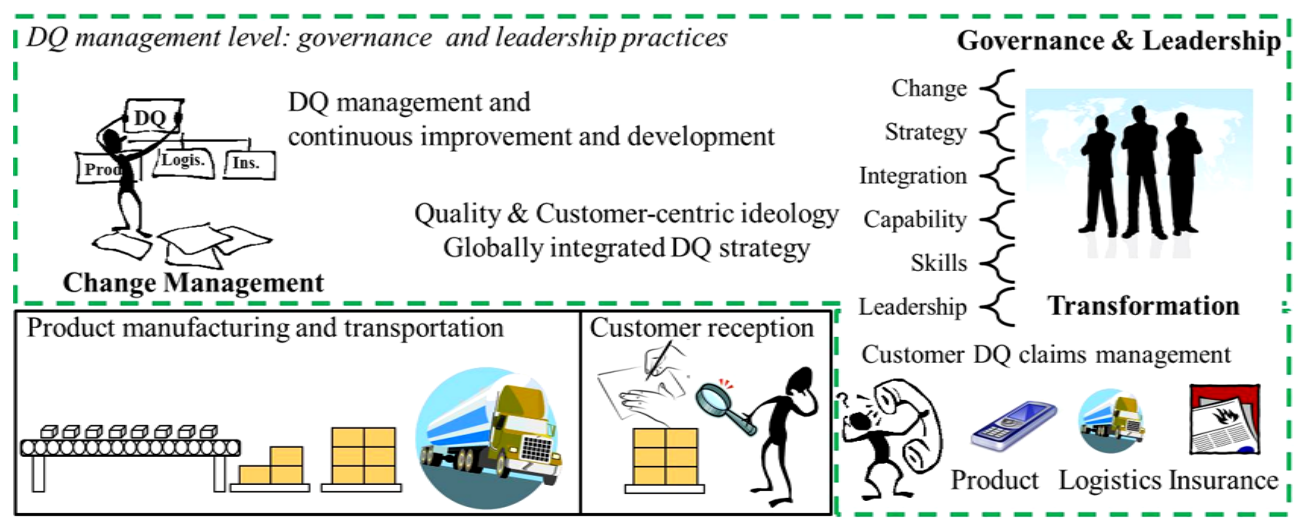

DQ operational level: processes, practices, activities, reporting, interaction, finance, insurance, etc.

Figure 1. Research focus area: the DQ management level and customer DQ claims management. 
shows trade customers' perception and reported non-conformances, whereas the Corrective Action Preventive Action (CAPA) provides a solution to the non-conformance.

This research presents how Nokia, in its logistics and supply chain unit, embarked on several years journey to develop its DQ management and leadership practices to become a quality and customer-centric organization. We present the change effects on Nokia's overall DQ performance and DQ management during years 2008-2012. On a global scale, Nokia's expertise is highly reputable in supply chain management and Nokia was a leader in optimizing and managing all aspects of its global supply chain management. Nokia gained success worldwide with short life-cycle products, and efficient supply chain management was central to its success. Nokia was ranked as number one in the 2007 Advanced Market Research top 25 ranking, and was described as a pioneer in value chain management [1].

During years 2008-2012, Nokia sold its mobile devices through operators, distributors, and traders. Here, these intermediates are defined as the trade customers (later referred also as customer). These customers were responsible for the marketing of the Nokia products with the small distributors. We will not expand our research upon the Nokia's mobile phone research and marketing or its overall leadership practices. At Nokia, in the early 2000s, the demand to gain global trade customers' perception visibility triggered global supply chain improvement activities. Nokia's management decided to seek solutions to improve the organization's quality and customer-centric operation without compromising cost, efficiency, or coordination. Widespread changes to the DQ governance and leadership, the constitution of a new integrated DQ strategy, and the establishment of new global end-to-end DQ process, practices, and IT solution were required to drive the DQ and CAPA management globally.

The following sections describe the key principles, structures, and relational mechanisms of our DQ solution, DQ change management activities, and instances from Nokia's DQ practices. We conclude by validating the findings of the globally integrated DQ strategy and transformation.

\section{Literature Review}

\subsection{The Interconnection between Supply Chain, Quality Non-Conformances and Insurance}

With the world economy in a fragile state, top corporations must adapt to survive and take extreme actions to ensure customers' satisfaction. Muffato and Panizzolo [2] and Jablonski [3] wrote that customers determine the service quality level and the customer satisfaction improves by providing products and/or services whose features will satisfy customers' requirements and needs. As stated by Garvin [4]: "product quality is synonymous with meeting specifications. The critical issue is whether the final product conforms to the design and performance standards set for it”. Chang [5] wrote that in a supply chain, the customer definition includes also many in-between customers, for example, suppliers, manufacturers, and sellers. Therefore, to ensure customers' satisfaction, the core enterprise and all the members of the supply chain must pay attention to their end-customers' and preceding customers' needs and expectation. According to Chang [5] an organization and its suppliers are dependent on each other, and the company's key goal should be to strengthen the mutually beneficial partner's relationships with suppliers. Companies must regard their suppliers and stakeholders, because the end-to-end quality and customers' satisfaction are performed and impacted by all the supply chain members.

Implementing an integrated supply chain management strategy will bring significant changes into companies' culture and stakeholders' operation throughout the entire supply chain. Logistics management is considered to be the origin of the Supply Chain Management (SCM) [6]-[8]. SCM includes, for example, sourcing of raw materials, marketing, product development and manufacturing, supplier management, and customer relations [9][11]. Chang [5] wrote that companies should analyze the end-to-end operational information and performance, including their supply chain members. Then, the potential problems, in any stage of supply chain, can be found and to make a correct and timely decision to avoid or rectify the problem.

All deliveries (such as product, service, and logistics) do not always work out successfully. Therefore, quality claims originate when products do not conform to requirements. There are various ways to categorize quality non-conformance claims by the type of deviations, such as: product claims, logistics claims, and/or insurance claims. Damages and losses impact all members in a supply chain. Skorna and Fleisch [12] and Peleg-Gillai et al. [13] identified that transportation is vulnerable to various kinds of risks, such as: losses, thefts, damages due temperature, humidity, tilts, shocks, and in-transit and customs delays. Wallenius [14] states that the cause of 
these damages are handling related errors, such as sudden pulls when moving cargo, inclination and hits, dropping the cargo, packaging errors, negligent handling, and flawed warehousing. In a supply chain, one of the key elements is risk management. Jüttner [15] wrote that companies should include all stakeholders and entities, including transportation, into their risk and vulnerability identification. Any disruption in supply chain may cause significant financial impacts and loss of sales. Therefore, insurance is closely bound to supply chain and logistics management and it is an important risk management tool for companies.

The term "London Market" refers to all the international and UK insurance and reinsurance practitioners based in London, including both Lloyd's insurers, and individual companies. According to Peverett [16], an insurance claim is the actual application to invoke the benefit of the insurance promise. In the event of a loss, policy holders must file a written insurance claim before money can be disbursed to the insured. The insurance company, however, has the authority to approve or disapprove claims based on its own assessment of circumstances and facts presented by the insured and the neutral third party loss adjuster [26]. The global insurance markets have defined protocols for the handling of claims and the responsibilities of each party. Marine Insurance Act [17] and Lloyd's [18] defined: "Marine insurance is an agreement whereby the insurer undertakes to indemnify the assured, in the manner and to the extent agreed, against marine loses".

All types of transit can be insured under Marine policies, such as: transit by sea, road, rail, air, and registered post. The Incoterms rules are important for international commercial transactions and are a series of pre-defined commercial terms published by the International Chamber of Commerce [19]. The Incoterms are widely used to reduce and/or remove different interpretations of the rules in different countries, and to clearly communicate the tasks, cost, and risks associated with the delivery of goods and transportation [20]. Marine cargo insurers in London markets recognize loss prevention as a proactive instrument to manage risks and non-conformances [21]. Therefore, it is important to develop and maintain knowledge of the required insurance processes, practices, requirements, standards and regulations globally.

\subsection{The Importance of Change Management, Leadership and Quality Practices}

Active, ethical and participative management is needed because people are the most challenging dimensions to manage. It can be challenging to change the current operation, especially in organizations where a certain wayof-working approach has prevailed for many years. Companies need courage to make contradictory solutions and not to follow the common approach, for example, defined by the insurance markets. Nevertheless, it is possible to implement the planned change activities successfully. But, the change must be directed by strong and knowledgeable leaders. The leaders need to have knowledge of the tools available to achieve a positive change, and to understand their role in initiating and sustaining the change worldwide. As highlighted by Kotter [22] and Chang [5], ownership and active leadership are needed to respond to the customers' expectations, develop the practices, and to establish the development strategy and clear and realizable operations targets. Therefore, successful change management and leadership approaches require more than only process and regulation descriptions and documents.

When changes in operation are needed, companies need to identify: how to deliver the change, where to start, who to involve, and how to sustain the change. They also need to know what should not be changed. Well-defined and implemented governance and leadership are important enablers to success in a global operation. The management system of shared governance empowers all employees into the decision-making process, which requires effective leadership and examination of the organization's structure and culture [23] [24]. Edmonstone [25] wrote: "shared governance aims to develop collaborative relations, improve quality and effectiveness, increase staff confidence, assist in personal and professional development, encourage the sharing of information and effective communication, facilitate development of new knowledge and skills, increase professionalism and accountability, sharpen direction and focus and reduce duplication of effort”.

Carmignani [26] states that various quality management initiatives are important part of the SCM practices in order to improve product quality and development. In Figure 2, we defined that the ISO 9001:2008 eight quality management principles form the foundation for Kotter's eight steps change model, which is led by leadership factors. The quality management principles and leadership factors address a strategy to improve the quality and performance and to responding better to the customers' perception. The ISO 9001:2008 [27] standard defines eight quality management principles (Figure 2): “1) customer focus; 2) leadership; 3) involvement of people; 4) process approach; 5) system approach to management; 6) continual improvement; 7) factual approach to deci- 


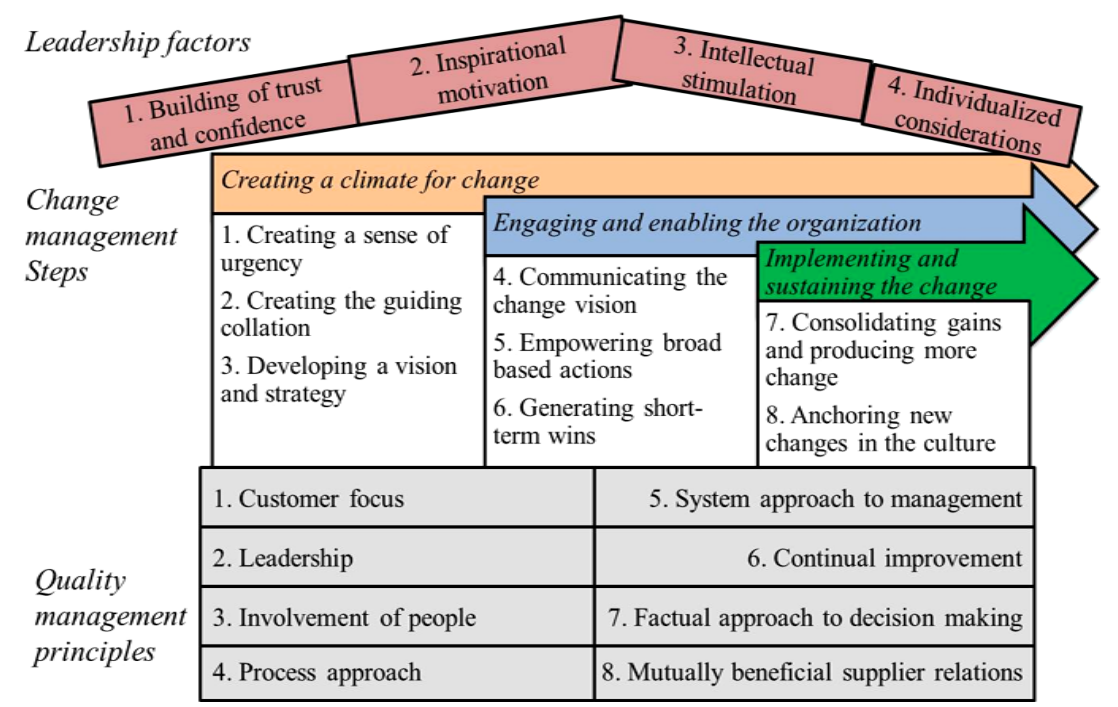

Figure 2. Kotter's change model in DQ context (adapted from ISO 9001: 2008 [27], Kotter [22], and Nissinen [29]).

sion making and 8) mutually beneficial supplier relations”. Kotter [22] defined eight steps change model (Figure 2). The change model steps are: 1) creating a sense of urgency; 2) creating the guiding collation; 3) developing a vision and strategy; 4) communicating the change vision; 5) empowering broad based actions; 6) generating short-term wins; 7) consolidating gains and producing more change; and 8) anchoring new changes in the culture. Similarly, based on the management ideas of quality, a quality management system should promote active participation of all the members and facilitate the quality control implementation over the entire supply chain system.

Kotter [22] pointed out that only leadership can motivate the actions and behavior, and blast through the many sources of corporate inertia, and only leadership can anchor the change into the organization culture. Therefore, managing change is important, but leadership is needed to make the change happen. As Cyr [28] wrote, trust is an essential ingredient between organizations. Nissinen's [29] Deep Leadership model has been used in the Finnish defense forces' leadership training since 1998 and in the civil organizations' leadership development. Nissinen's transformational leadership factors are (Figure 2): "1) building of trust and confidence; 2) inspirational motivation; 3) intellectual stimulation; and 4) individualized considerations”. Leaders organize, inspire, influence on behavior, and change the course of events. Because of this, active and participative leadership plays a critical role in implementing decisions successfully and overcome resistance to the changes.

The employees' role and increased participation in the change process are emphasized by, for example, Total Quality Management, business reengineering, and lean management [30]-[33]. True involvement is vital for delivering products and services, and to achieve its business objectives. According to Fawcett et al. [34] and Chang [5], in a supply chain, an open and supportive work atmosphere should be established. All employees, of all partners involved in a supply chain, must understand his/her role and responsibility in the supply chain system. They need to learn key principles, skills, technologies, and proactively solve problems.

Currently, the need for rapid changes and improvements is continuous. A widely-known continuous improvement approaches are Deming's Plan-Do-Check-Act (PDCA) cycle (Deming [35]) and Six Sigma cycles [36] [37]. Six Sigma's approaches, for example, can be used to improve quality throughout the supply chain and to identify performance gaps. The idea of these (Deming's and Six Sigma) cycles is to repeat continuously the cycle's steps. These have emphasis on employee involvement and teamwork, systematizing and measuring processes, and reducing defects, variation, and cycle times. Chang [5] states that throughout the supply chain process, the core company, and the other members (such as Logistic Service Providers (LSP), suppliers, and sellers) must respectively improve and ensure the continual improvement of their products and services. The basic idea of continuous improvement is that an individual or organization continuously works on improving: themselves, a product, and a work method.

The ISO eight quality management principles [27] highlight also the importance of documented processes and 
system approach. Documented processes ensure that everyone who is involved in a certain process or service will share the same viewpoint, and will know how to consistently follow the required steps. All stakeholders must hold a mutual understanding of the long chain of activities, including compliance with laws, regulations and rules. According to Harrington and Mathers [38] and Cole [39], the ISO 9000 standard stresses the need and importance of documented processes and system approach. Therefore, third-party auditors should ensure that an organization is following its documented practices. In system approach, it is important to define the importance of individual procedures, the interaction between different kinds of company's processes, and the inputs and outputs that link these processes together. Chang [5] recognizes that in a supply chain system, harmonious supply chain operation is secured by identifying and managing the processes and their effects to realize high quality. Therefore, the company should confirm the mutual dependence relationship among the processes, and break the boundaries among supply chain members by constructing and integrating the processes.

\section{Methodology and Research Hypotheses}

According to Näslund [40] action research is a preferred method to bring together logistics researchers and practitioners. However, action research is infrequently used in logistics research [40]. The challenge, when using traditional survey research methods, is that it simplifies complex "real-world" problems, and achieving any tangible benefits from the practitioners' point of view seems to be small. Näslund [40] wrote that logistics researchers should understand better the world of practitioners to gain extreme relevance by understanding what is going on within organizations. Checkland [41] considered that researchers should more actively participate in an organization's projects and/or change processes. Instead of remaining as an outsider observer, the core idea of action research is to participate in the practical problems, develop new processes and solutions, and observe the change effects [40] [42]-[44].

In this research, we utilized an action research method, and the authors' hands-on experience to present the outcomes and analysis of the DQ operational environment elements, the quality and customer-centric ideology, the change model, DQ capability elements, and DQ governance and leadership model. We also present how Nokia's DQ change management activities impacted on global DQ performance during the timeframe. This study suggests that the following set of hypotheses may be associated significantly with DQ success and performance:

H1: A globally integrated delivery quality strategy can enable better oversight and control to manage all delivery quality claims more efficiently worldwide.

H2: The DQ operational environment elements can provide a frame to be utilized in DQ management and practices development and global level transformation, and to determine the needed operational level DQ processes, practices, usage, and change management activities.

H3: In a large-scale global company, active and participative leadership is in a critical role to achieve the global transformation and implement the customer-centric ideology into the company's overall delivery quality operation by building and managing global delivery quality operations, practices and culture.

This research may not be classified as a full case study, because it only presents short illustrations, analyses, and change evaluations in DQ operation at Nokia. The DQ development activities and evaluations were performed by a group at Nokia during years 2008-2012, and three of the participants in the group were the authors of this article. Nokia has many competitors, and therefore Nokia is restrictive to make public their successes and failures, especially when it comes to their core supply chains processes. For confidentiality reasons it is not possible to present in detail Nokia's operational level DQ activities, solutions, and DQ category results. However, the aim with this research is to present the outcomes and analysis of global DQ transformation and the effects of leadership on global DQ performance results and culture.

\section{Research: A Globally Integrated Delivery Quality Solution}

When a company decides to focus (more) on quality and customer-centric operation, it means that a cultural change in operational and organizational level is needed. The following sections will present our globally integrated DQ strategy solution. The three main transition elements were: One, The Integrated DQ strategy (Section 4.1) combines product and logistics issues with insurance issues. This strategy enables total visibility of all DQ claims globally and a consistent way to respond in an efficient and timely manner. Two, The DQ Management and Operational Environment Elements (Section 4.2) provides the overall operational environment for DQ management and development. The DQ elements provide customer-centric approach to manage non-confor- 
mances and processes and practices. Active and efficient DQ network management and dialogue among the members are important elements to increase trust and satisfaction across DQ stakeholders worldwide. Three, The DQ Governance and Leadership practices (Section 4.3) are common and shared with DQ and CAPA, and the same regularity requirements apply to both of the areas. In this research, we will not expand upon CAPA process and practices further, but we want to emphasize the importance of the well-defined and interconnected CAPA practices with DQ to achieve enduring changes in overall quality.

We start with a DQ claims management example to illustrate the potential operative DQ claims management phases (Figure 3). This generic DQ claims management example is created based on literature (such as, OECD [45] guidelines and claiming instructions of Lloyd's [18] insurers) and authors' hands-on experience. The example focuses only on describing the potential claims management phases and it excludes detailed process definitions or work instructions. This example includes seven main phases.

At phase 1: a customer provides the non-conformance information, such as: product deviation, missing or incorrect item in sales pack, missing/stolen shipments, damaged shipments, thefts/hijacking issues. At phase 2: based on the information, a customer claim is created (logistics/insurance). The basic information and documents, evidences, and Incoterms are documented and stored for detailed analysis. At phase 3: the claim will be analyzed and verified by several stakeholders (for example sales unit, factory and insurance). Analysis activities can include several checks, such as delivery document data, handling parties, X-ray pictures, quality audits, transporting method and route. At phase 4: after analysis, the decision and claim solution will be provided (for example, no actions, replacement, payment, false alarm). At phase 5: for insurance claims, the letter of subrogation will be prepared, as this secures the recovery rights against, for example, LSPs. According to the defined insurance terms and conditions, the customer is responsible for communicating deviations in writing. Issues must be communicated within agreed amount of days after the delivery of the goods. This burden of proof is used in the recovery claims process. At phase 6: an insurance recovery claim is issued when needed. A recovery claim is a claim against the LSP to recover the value of the loss the LSP is responsible for in accordance with the agreed agreements. At phase 7: the claim solution and possible CAPA activities are communicated and the customer claim is closed.

At Nokia, during years 2007-2008, the high demand of enabling better customer perception transparency required adjustments to improve the responsiveness and flexibility of existing delivery quality practices, globally. The growth of Nokia's production volume and product diversity put pressure on the organization to manage the increasing number of transactions and deliveries. Simultaneously, advances in Information and Communications Technology methods allowed allocating logistics DQ responsibilities closer to the responsible organizations, business units, and individuals. In the early 2000s, Nokia's factories managed DQ and CAPA activities in isolation from each other. Each factory developed and operated factory-specific CAPA practices. Corrective actions (CA) were steps taken to remove the causes of an existing non-conformity and preventive actions (PA) to remove the causes of potential non-conformities. With growing volumes and product diversification, true global DQ transparency was not available.

Based on our analysis, Figure 4 presents a generalized illustration of the initial change model before starting the global DQ transformation. This initial change model has similar elements with Kotter's eight steps change model (see Figure 2). The initial model included three main phases and eight steps. The phases were: 1) starting the change; 2) implementing the change; and 3) sustaining the change. The eight steps were: 1) create a need for change; 2) establish the team; 3) develop a process; 4) communicate the process; 5) implement the process into the operation; 6) establish the metrics; 7) monitor the process; and 8) monitor the metrics. It is worthwhile to point out that the former DQ operation and process focused mainly on internal DQ management and it did not include, for example, other stakeholders or external parties.

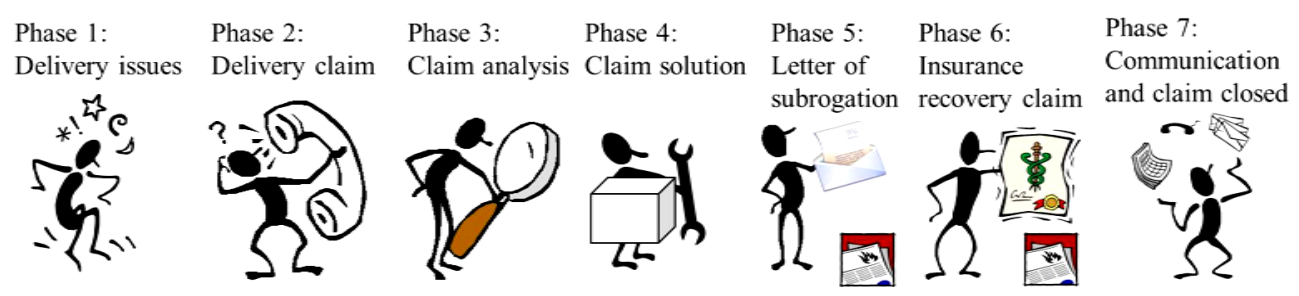

Figure 3. General DQ claims management main phases (logistics and insurance). 


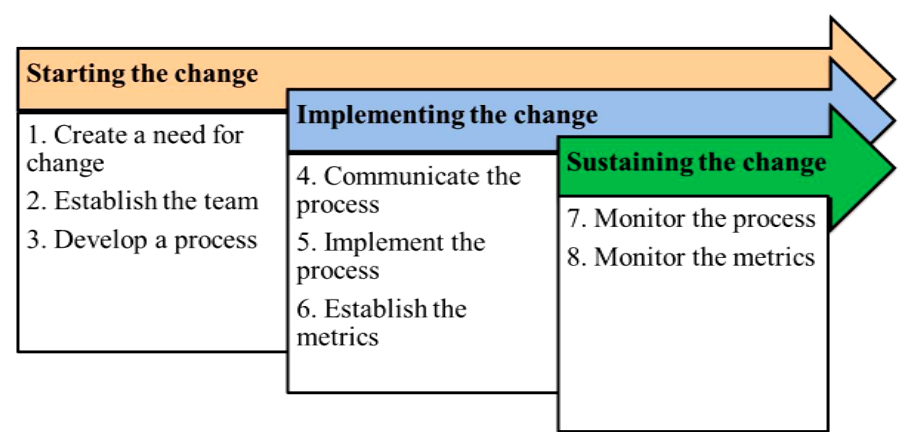

Figure 4. The initial DQ change model.

During the year 2008, it was realized that the customer perception was not clearly built into the former DQ practice, and therefore "good quality" was Nokia's own internal interpretation. Based on our observation and experience, various sources triggered the entire redesign of $\mathrm{DQ}$, such as the process being inadequate, the IT-tool not supporting the operative work, the data in the systems not reflecting reality, systems not including enough data/information, limited scope, personnel were working in silos and had a lack-of-accountability attitudes, and no clear ownership (at the individual/group level). In addition, the existing IT system for DQ claims management limited the DQ development possibilities. Further emphasis was needed to bridge the gaps between various functions and departments, which triggered development of the new global-level DQ and CAPA process models.

The decision to design a novel DQ solution was a contradictory approach, but it enabled the possibility to develop the DQ solution without limiting the stakeholders' needs, requirements, or demands. Therefore, the initial change model was not sufficient for extensive global change management activities. It was realized that transformational change management and leadership approaches were needed to incorporate the required change activities and quality and customer-centric ideologies into the operational level activities and culture throughout the internal and external stakeholders worldwide. In this research, the stakeholders were, for example, Global Business-to-Business (B2B)/Trade Customers, Research and Development (R\&D), Sales, Operations, Manufacturing, Forward and Reverse Logistics, 3rd-party logistics (3PLs), Logistic Service Providers (LSP), Suppliers, Hardware (HW), Software (SW), Services, Insurance Providers, Occupational Health and Safety, Brokers, Reinsurers, etc.

\subsection{A Reformist Globally Integrated DQ Strategy}

We consider DQ and CAPA as one of the company's core processes and practices. Companies may execute DQ activities with only few tangible companywide effects. One of the reasons may be the failure to connect customers' perceptions to operative activities and management. A globally integrated DQ strategy enables total end-to-end DQ management by combining product, logistics and Marine transit insurance claims activities. Normally these three areas are managed separately in various IT solutions and processes. This combination enables, for example: increased DQ control, validation, increased knowledge and information, synergies, savings in time, and all activities are completely owned by the company worldwide. This may result in vastly improved quality and customer perception and reduce costs, losses, and the overall number of claims to manage. At the same time, a well-grounded change management target and communication are vital elements to achieve the needed commitment and buy-in among the global supply chain stakeholders worldwide. The new strategy must bring substantial and positive improvements into the existing situation, for example, improved operational level execution, increased amount of available information for decision making, reduced the amount of IT solutions, and savings in time in operational level.

It is uncommon to require an insurance company to use a service purchasing company owned processes and IT solution to manage the service purchasing company's insurance claims. Typically, service purchasing companies pay insurance companies to manage the insurance claims practicalities, and to use tools and processes provided by insurance companies themselves. In this kind of setup, the insurance companies, for example, dictate strict constraints and costs on the IT-systems used, how and when the tool can be developed, and what information is stored. In fact, the ownership of the insurance information stays with the insurers, which can be an 
important detail in certain insurance claims situations. These are also additional costs incurred by the company buying the service. Clearly, this approach restricts service purchasing companies' visibility and development possibilities for their insurance claims management. The insurance companies' tools are not built for crossfunctional management purposes or for including different kinds of needs originating from various stakeholders. The insurance company tools are not interactive, and therefore, information cannot be added to the tool without involvement of the insurer. This type of situation will create a "double IT system" situation where some information is stored in the service purchasing company's own IT-system and some in the insurance company's IT-system. In addition, insurance companies typically focus on denying claims (not paying) unless it can be proven not to be the customers' responsibility.

The biggest benefits of a globally integrated DQ strategy will be achieved when processes and practices, operational level activities, and information sharing, conducted by various stakeholders, have been defined and implemented worldwide. Certainly, the insurance field will bring various requirements and regulations that need to be followed, for example, financial elements, country specific laws and regulations, Incoterms, and other insurance specific practices that must be taken into account during the process and IT solution development. However, a successful combination of the specific fields, such as product, logistics and insurance, can improve company's total claims management practices and provide important information, which improves company's communication capabilities towards customers, and increase knowledge. Globally integrated DQ strategy increases the claim detail and speed of information availability, clarifies roles and responsibilities, and sets clear targets and expectations throughout supply chain and enables customer-centric process. From a quality perspective, the insurance claims should not be separated from the total amount of delivery deviations, and those should be reported and analyzed together with product and logistics claims.

During years 2008-2012, Nokia was unique in the world by using its own global process and IT system to manage insurance claims. Nokia provided the guidance and requirements for all stakeholders regarding all DQ non-conformances. Nokia had its own captive insurance company (Nokatus), and all Nokia transit risks (such as: transportation, handling/packing at third-party warehouse, delivery to the customer) were insured by this captive insurance company with considerable deductibles involved. Nokia's approach included several customer-centric aspects, which differed from the typical insurance claims management practice, for example, accepting and quickly paying customers' claims unless it could be proven that the claim was clearly the customers' responsibility. Depending upon the claims' total financial amount, the impact either stayed with Nokia, or by exceeding certain defined limits, it was submitted to reinsurers. Insurance claims' financial value varied greatly. The largest single insurance claims were typically millions of Euros caused by a hijacking, whilst the smallest claims were just a few Euros. All insurance claims were handled by Nokia's external claims-handling supplier. The claims-handling partner performed the activities according to the Nokia's process in the Nokia's DQ IT system (not in insurance company owned IT system). This approach enabled the total control and ownership of product, logistics, and Marine transit insurance claims, and to be fully remained inside Nokia and having direct visibility of all claims-related information.

All recovery claims (where actual transporter was financially responsible) against responsible LSP's were handled by Nokia's external claims-handling partner. Reasons for not issuing a recovery claim were, for example, hidden damage, late notification, claims' financial value was too small, or it was force majeure claim. The ultimate claims decisions and specific claims management situations were guided by Nokia and Nokatus. The claims-handling partner managed the insurance claims, and the LSPs were involved in claims handling and loss prevention activities. All claims were reported to the insurance broker and to Nokia. The claims-handling partner complied with the Nokia-defined customer-centric rules when managing customer claims, reporting, and communication. The claims-handling partner was responsible for recovery management activities with LSPs, reporting of the status to the various stakeholders, and these were guided by the Nokia insurance in coordination with the logistics teams. This approach supports Hypothesis H1, where globally integrated DQ strategy enables better DQ oversight. Good case visibility and knowledge made it possible to manage recoveries from LSPs more efficiently and timely, resulting in a higher recover rate for Nokia, and the recovery results were significantly higher than the London market results.

\subsection{Defining the Global DQ Management and Operational Environment Elements}

The Russian proverb adopted by Ronald Reagan during 1980s, "Trust but Verify”, applies in DQ management. It is notable that retaining all DQ activities in-house is not required. However, accountability, ownership, and 
supervision should not be outsourced to another company. Companies could look for cost savings by allocating actions and accountability to the suppliers, such as performing material quality assurance activities. Based on our experience, the responsibility could be given to suppliers to a certain extent. But, when a situation arises, the core-company would be considered as the accountable party and face the impacts, such as reputation, loss of sales, penalties, and lawsuits. Consequently, the company's role in educating the suppliers is important. The company must continuously ensure that the stated standards are fulfilled. If the supplier does not have the needed skills, expertise, tooling, and processes in place, then the company will have a false and unrealistic expectation of supplier's quality and output levels. Therefore, companies need to be prepared to assist the suppliers in achieving their targets by building two-way bridges of trust, competency, and expectations.

We explored the role of customer-centric organization, end-to-end claims management, and enhanced communication among the global DQ network. The DQ capabilities targeted at gaining companywide customercentric operation visibility into customers' perception, customer perceived quality of the deliveries, and DQ performance. In this approach, all stakeholders in the supply chain hold a significant role in DQ and CAPA success. The main DQ management and operational environment objectives were to capture customers' perception, manage end-to-end DQ issues and claims, ensure fast and clear resolution and communication, and implement effective corrective and preventive actions. This approach supports Hypothesis H2. We also emphasize the criticality of defining and agreeing explicitly the needed operational level activities, and global implementation of those on all stakeholders. It is notable that the operational level activities vary based on the company, context, and industry.

Figure 5 shows the identified DQ operational environment elements. These DQ elements emerged from our research and were created based on author' hands-on experience, literature, and lessons learned from Nokia's DQ solution. The identified DQ elements combined product, logistics, and insurance into the same management and execution flow. Throughout the solution, the main themes were: DQ governance and leadership (Section 4.3), supply chain stakeholder and network management, communication among the DQ network, DQ culture and reputation (significant impacts on trust and actions), and DQ performance measurement (such as DQ metrics, targets, and reporting practices).

Figure 5 shows that a significant DQ capability was to establish a quality and customer-focused DQ organization, which includes customer interaction and logistics partners clearly into the overall DQ strategy. Accordingly, the DQ operative actions should not only be limited to material-related issues impacting deliveries. DQ should include also customer satisfaction elements, for example, what it is like to work with company's personnel, their attitude, and their knowledge of products and services. Therefore, customers' perception, feedback, non-conformances, and evidence shared by the customers are starting points for detailed analysis and knowledge. Similarly, several external factors will influence the DQ processes and practices, such as company and context specific requirements, standards, (country) specific laws and regulations, Incoterms, specifications and contracts, and claims management standards and best practices.

Figure 5 shows that a global DQ IT solution, which is strongly interconnected with CAPA, will be an important claims management enabler. The information in the IT solution provides an open availability to customer claims and data by allowing immediate sharing of cases, best practices, challenges, solutions, and contact persons. In fact, stored and analyzed DQ information and data enables learning possibilities, enhance communication, and knowledge. The primary approach should be to keep the IT solution as fast, flexible, and easy-to-use regardless of an expectation to establish a strict tool category and group definitions. In our global IT solution approach, one specific group's needs cannot be allowed to impact or limit other groups' needs or future tool capabilities, speed, or customization.

Companies, which excel in supply chain, conceive and continuously develop their practices and network management among its supply chain actors and customers. Similarly, effective DQ network management and operative practices develop DQ culture by embedding the practices and ideology into the DQ members' behavior and actions. It is notable that focusing only on the company's own personnel and activities is not enough. The end-to-end DQ operations needs to include all supply chain members. Clearly, this requires open communication and cross-functional cooperation among all supply chain members, where none of the stakeholders are able to achieve the targets alone. Especially, the leaders and top-management must demonstrate commitment and credibility to the practices and changes, and where words and actions correspond without inconsistency (Figure 5). Similarly, DQ leaders should continuously ensure that the implemented DQ practices and culture remain globally, and provide the needed corrections and training. 


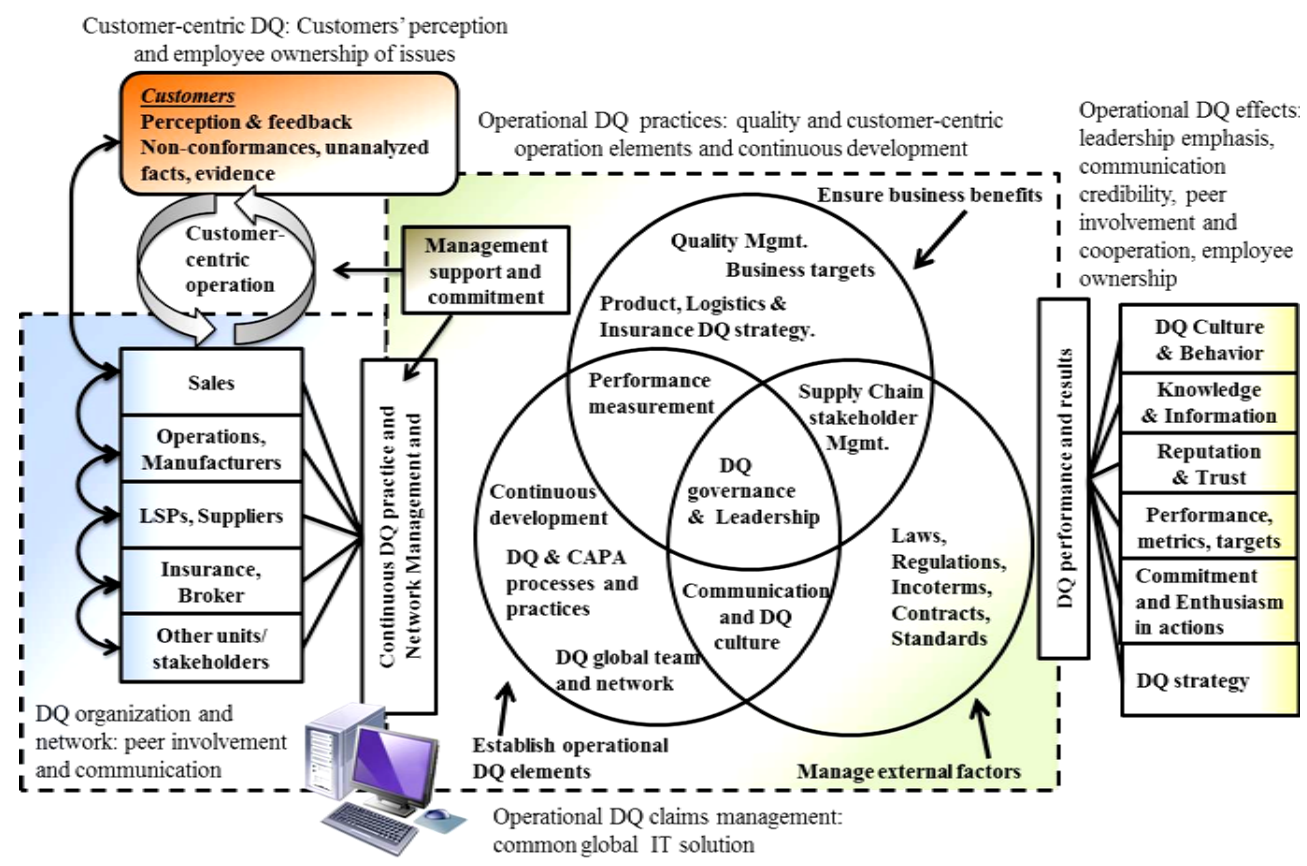

Figure 5. The operational DQ environment capability elements.

It is notable that the implemented global operative activities and practices are the core of DQ's operational success. Therefore, the DQ processes should be planned with "the end in mind" and starting with the desired output and/or outcomes and working backwards through the supply chain. Process planning can be started by defining the needed outputs and the customers, and design the processes and reporting accordingly. In addition, the focus should be on capturing customers' perception as thoroughly and timely as possible. The global DQ processes may, for example, provide global guidelines on how to manage customer claims, and when to initiate CAPA activities. The global DQ processes and practices provide a frame for the operative activities. However, the company and field specific operative activities, such as customer claim checking, taking $\mathrm{x}$-rays, sending replacements, communicating with customers and stakeholders, and using the required IT solution need to be defined and trained explicitly.

The target is that the global DQ practices impacts positively on customers' and stakeholders perception and satisfaction. In our DQ approach, a quality and customer-focused DQ culture is focusing on fixing the nonconformances, conducting efficient follow-up and communication activities, explaining the progress that has been made, and showing continuing concern and appreciation to the customer and supply chain members. DQ and CAPA practices impact, for example, financial elements (such as replacement and shipping costs, personnel extra work and salary, insurance payments), DQ processes and practice culture, actions, and DQ trust and reputation. Undoubtedly, substandard DQ and CAPA management, culture, and issue-prevention success will eventually be visible to the customers and supply chain members, which may have major impacts on reputation, customers' satisfaction, and supply chain quality among its members.

Nokia's global DQ process provided guidelines, for example, on how to manage all customer claims. During years 2009-2011, roughly 70 percent of all claims were logistics claims and 30 percent were insurance claims. Efficient DQ and CAPA practices and culture positively impacted on global DQ performance, and increased the customers' satisfaction. At Nokia, customer claims included all faults caused by factories and LSPs, and design and material faults found by customers. Some customers had strict requirements for packaging damage, and could refuse the entire delivery for minor damage. Deviations were also caused by customers themselves, and the customers might request free-of-charge (FOC) replacements or repairs from Nokia. These FOC replacements were approved on a case-by-case basis.

At Nokia, a novel global IT solution was created for DQ and CAPA, (which replaced seven IT-tools) and Nokia required all parties to use this global IT-tool for all DQ claims management. Because of this approach, Nokia had the possibility to collect and store a great amount of information of the claims, to develop the IT-tool to ful- 
fill different stakeholders' needs, to utilize the stored data for CAPA, and to create different kinds of reports for different stakeholders. A globally integrated IT solution provided new learning and knowledge transfer possibilities by having the same information and solutions utilized by all relevant supply chain stakeholders worldwide. This open availability to customer claims and data was a notable feature as the factories and sales units around the world were able to share their knowledge, findings, and solutions. India and Brazil, for example, experienced similar kind of challenges with excessive rain and flooding, and therefore, both factories were able to utilize the same information and solution to fix the problems. The new IT solution allowed knowledge utilization and at the same time increased the global transparency of the complete customer perception and issue solution data stored in the IT system. The establishment of the end-to-end DQ process and IT solution allowed Nokia to respond more efficiently and timely to customers' perception. More material to validate Hypothesis 2 is also presented in Chapter 5.

\subsection{Defining the Global DQ Governance and Leadership Practices}

At some point, a quality and customer-centric operation typically requires transformational governance and management system improvements to successfully achieve the expected business benefits and targets. The governance is needed to guide and monitor the values and goals of DQ through policy and procedures. A customer-focused organization can be achieved by establishing an active and nurtured customer network and relationship management. A customer-focused DQ organization understands customers' perception, has knowledge to respond accurate and timely, and aims to improve customer satisfaction. Customers' perception and feedback can be received during customer meetings and satisfaction surveys and in customer DQ claims.

We explored the DQ governance and leadership practices where customer-centric ideology was in the center of all operation. Based on our observations and analysis, it was evident that after the change management activities, it is important to ensure that the changes were embedded into the operational level activities. Therefore, governance and leadership activities were in a significant role to promote the expected operations. Figure 6 presents our six main DQ governance and leadership model elements after the transformation activities to ensure the operational level mode-of-operation sustainability. The DQ governance and leadership elements were: 1) customers' perception; 2) strategies; 3) processes; 4) resources; 5) situational targets; and 6) results.

In this governance approach (Figure 6), a customer-centric organization continuously maintains business relationship with customers and by that receives customers' perception, which drives the strategies (at various levels). Strategies direct the processes, and the processes are used and measured by the resources. Situational targets indicate the operational focus areas and expectations. Resources influence results, and these indicate the success of the process. Results also trigger process improvement requirements for the processes itself. Results confirm the strategies, either by supporting the selected strategy, or by indicating the need for its changing. In this approach, leaders need to take ownership and commit to the responsibility, hold the needed professional

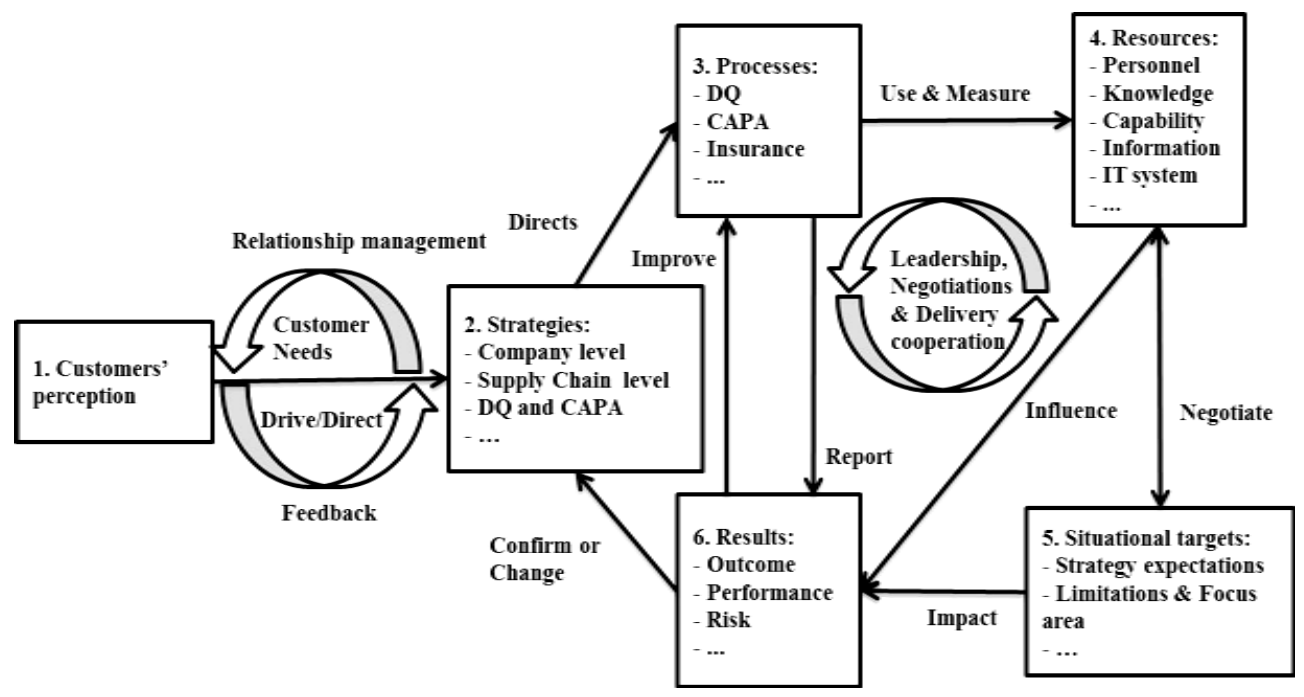

Figure 6. The DQ governance and leadership model. 
skills and knowledge to guide and influence others, and demonstrate expertise. DQ’s success results from factbased decision making, strong, ethical, open, and transformational leadership, having top-management support, and true interest and commitment. This approach supports Hypothesis H3.

It is notable that especially the DQ target setting requires detailed analyses, review, and discussions to agree on the targets. Based on company's overall strategy and expectations, the DQ leadership team initiates the DQ target setting negotiations. In this governance and leadership solution (see Figure 6) the target setting should not be a top-to-down approach. Instead, it should be bottom-to-top, where the targets are negotiated based on the feedback received from field and customers. The leadership team formulates the initial proposal, and provides the needed guidance, limits, and framework for negotiations. During the negotiation phase, various aspects, such as: anticipated total production and history, current performance, known market-specific changes, distribution channel, product focuses, and customer requirements, should be examined and discussed to understand possible effect on the ability to respond to the defined targets. The agreement of the DQ targets is formulated during several negotiation rounds and the end-result represents the best possible set of situational targets. In this approach, achieving the targets requires cross-functional cooperation with all stakeholders, and the idea is that none of the stakeholders are able to achieve the targets alone, which embraces efficient network and relationship management. This metrics and target setting approach supports Hypothesis $\mathrm{H} 3$.

The DQ performance and result should be measured based on agreed targets and metrics. In our solution, the main global DQ metric is: Global DQ\% = (Total Claims/Total Delivery Lines $) \times 100$.

This global DQ\% metric consist of two performance level components: 1) amount of claims and 2) total amount of deliveries. In this global DQ\% metric, it is notable that all claims are equal despite the severity of the claim or quantity impacted, because the target is to achieve the customers' perception as throughout as possible. The idea is that one delivery can produce multiple claims, resulting in the possibility of a greater than 100 percent failure rate (one claim per failure type). For example: one delivery of 1000 units: is late (one "late" claim), has damaged packaging impacting five units (one "damaged packaging" claim), and one unit has an incorrect in-box item (one "incorrect in-box item" claim) for a total of three claims for the one delivery, or 300 percent incorrect. This "customer-perceived perfect order" methodology is quite a different defects-per-million (DPM) measurement (this same measurement methodology was also implemented in Nokia). Because of this specific DPM measurement methodology, it is important that DQ claims are classified under defined categories. Based on the categories, it is possible to globally measure which categories have the majority of the reported nonconformances.

At Nokia, DQ and CAPA activities were led by a global leadership team. This internationally dispersed team was responsible for global DQ and CAPA processes and practices, IT tool development, global support, and DQ and CAPA operative management. Successful global DQ management required that the leadership team possessed professional-level hard and soft skills (such as, hands-on logistics and insurance knowledge and leadership skills). Leadership team involved contacts from logistics, insurance, sales, operations, and business branches, which enabled the needed buy-in, respect, and commitment. The team had direct connections to various stakeholders and top-level management to share DQ and CAPA messages and impacts of critical non-conformances.

During the transition phase, the new DQ practices created resistance, and personnel's true involvement was crucial for the success. Successful change implementation required buy-in and commitment from Nokia's topmanagement and from the field. The global team's essential "way-of-working” ideology was to be a customerfocused organization. Customer focus ideology was critical when improving the customer requirements and satisfaction awareness throughout the entire organization, and customer relationship management was an important part of the overall DQ leadership work. The leadership team, having direct connection and discussions with customers, provided support for sales and factories problem-solving efforts. This required personal interaction by visiting with various customers, sales sites, and factories to ensure complete understanding of the needs and challenges globally. The leadership team gathered and shared customers' requirements, feedback, and customercreated scorecards information inside the company with the responsible personnel and business units throughout the supply chain. At Nokia, the customers' claims and CAPA root-causes were classified under various categories. The categories had dedicated owners to own and manage the improvement actions and problem-solving activities. Dedicated personnel executed the processes that correspond to the defined targets and improvement demands worldwide. They brought their knowledge and expertise to the area and utilized the DQ IT solution.

The IT solution information enabled measurement of the results and realization of the defined targets. The DQ measurement and reporting brought the global DQ status and performance transparency to Nokia's top-level 
management. The overall DQ metric structure and target negotiations at Nokia were divided into: global targets, sales unit-specific targets, factory-specific overall and focus targets, and global categories targets. Focus targets depended upon specific customers, markets, and issues. Categories had designated owners (by name) whom were responsible for improving the area and conducting CAPA activities in their area. The target setting also included category-specific targets. Nokia also had several other metrics to measure the DQ performance besides the global DQ\% metric. Examples of these are sales unit DQ\%, cycle-time target (how much time different actors/units have spent), and category specific metrics (such as, Damage and Loss, Missing and Incorrect Sales Package Items).

\section{Results of the Research: Change Impacts and New DQ Change Model}

This research was motivated by the need to define basic DQ capability elements and solutions to capture customers' perception, establish quality and customer-centric DQ approach, and to achieve DQ transparency throughout the entire DQ supply chain. Nokia implemented several change management initiatives to its DQ approach, and therefore was an ideal case company. These DQ capability elements made it possible to improve organizations' knowledge and understanding of the DQ processes, practices, and solutions.

\subsection{General Action-Research Observations}

Based on our experience and Nokia’s DQ performance results, we observed improvements in Nokia’s DQ result and DQ practices and personnel behavior, which directly impacted Nokia's overall DQ results and success. By establishing a globally integrated DQ solution at Nokia, it was possible to achieve global DQ transparency of DQ activities. A globally integrated DQ solution made it possible to measure and guide all stakeholders with the same set of global accountabilities, activities, targets, and metrics. Based on our experience, the senior management buy-in was significant for the success. It was crucial that top-management recognized their role in achieving change and targets by promoting the DQ collaboration, teamwork, and management. Forming clear and shared business drivers to prioritize DQ activities to correspond with global targets and metrics was achieved. From a leadership perspective, it was important to understand the practical challenges in the field, the importance of open communication, provide support to clarify the impacts, and to identify potential DQ innovations. These observations support Hypothesis H2.

Based on our experience, active and participative leadership and well-defined and implemented DQ and CAPA practices were critical DQ success elements during the transformation and to improve overall customer satisfaction. The main DQ success factors were achieved, such as improved viability, joint vision and objectives, clarity of roles, processes and practices, top management commitment and support, leadership, communication, and trust. Critical DQ success factors were a customer-focused working culture, accountability, cross-dimensional peer cooperation and teamwork, continuous process and practice improvement, and failure and risk management across the entire supply chain. DQ governance and leadership practices were driven by goal-focused transformational management, possessing product, logistics, and insurance skills, and having market, trade customer, and internal process knowledge.

At Nokia, the DQ leadership team established the global DQ governance, policies and practices, quality expectations, reporting, and targets for the entire DQ community. We observed that effective governance structure and clarity of the global DQ ownership and accountabilities were achieved in the field. The global DQ leadership team had a significant role in global process and practices definition, management, implementation, maintenance, and training, across all stakeholders worldwide. Leadership team members conducted observations and management reviews, and provided guidance and instructions on how to solve the non-conformance situation according to the process, legal aspects, and country-specific regulations. The leadership team collected feedback from stakeholders, and planned the improvement activities accordingly. Continuous improvement practices were introduced and quality-related procedures included, for example, change management, incident management, customer complaint resolution responses, supplier management, and internal audits. These findings verify Hypothesis H3.

At Nokia, clear DQ process achievements were: 1) clarified roles and responsibilities between operations, sales units, LSPs, insurance company, and other stakeholders; 2) global DQ targets and performance standards; 3) global IT tool for DQ management; and 4) improved global and local level leadership and communication. These achievements support Hypothesis H1. Based on our experience and observation from the field, people in- 
dicated confidence in receiving an immediate reaction after raising a claim in the DQ IT system. It was observed that people occasionally submitted non-DQ issues into the DQ IT system because they knew from experience that they were guaranteed action, versus using other forms of communication, such as email. Users relied upon and trusted the DQ process and its effect. Effective governance and leadership practices were important enablers to implement, guide, and maintain the global DQ practices, and supervise the fulfillment of the stakeholders' accountability. The reinsurers of Nokia captive supported Nokia's global DQ strategy and results. They relied 100 percent on the information provided to them by the claims handling partner. It was also recognized that the awareness of risks and losses increased with the LSPs, thus increased loss prevention measures within their processes and with subcontractors.

\subsection{Global DQ Metrics Results}

Forming the global DQ metrics and targets setting approach was an important enabler to achieve the global DQ transparency, and display the global delivery quality perceived by customers. The target setting included various elements, which were specific, measurable, jointly achievable, realistic, and global time-targeted situational targets. The global situational targets ensured that all stakeholders were aware of expectations of them. Global DQ metric definition and implementation was needed to facilitate change and DQ performance. With quantitative and qualitative data, it was possible to provide the needed risk and performance visibility, compare costs and benefits, evaluate year-to-year performance, and share fact-based DQ communication to stakeholders.

The global DQ\% metric result has improved greatly during the years (Figure 7). According to the DQ percentage calculation rule, the lower the DQ percentage value, the better the delivery quality result. The actual DQ\% varied due changes in strategy, factory and sales unit focus areas, and new products were introduced. During years 2009-2011, the DQ\% performance improved 58.4 percent (presented in six-month periods, 1H09 includes financial calendar periods between January and June, year 2009). An improved DQ\% metric result indicated a successful globally integrated strategy implementation at Nokia. In Figure 7, January, 2009: DQ Logistics and Insurance process and a novel DQ and CAPA IT solution were implemented. September, 2009: Damaged packaging claims recording process enhanced. January, 2010: Accessory products added to scope and CAPA 1.5 process and IT solution release implemented. June, 2011: CAPA 2.0 process and IT solution 2.0 release implemented.

Nokia had a contradictory approach to implement its own DQ insurance process and IT solution for Marine transit insurance instead of utilizing insurance companies' standard services. Nokia required an external claimshandling partner to use the Nokia-owned process and tool for insurance claims management. The integrated

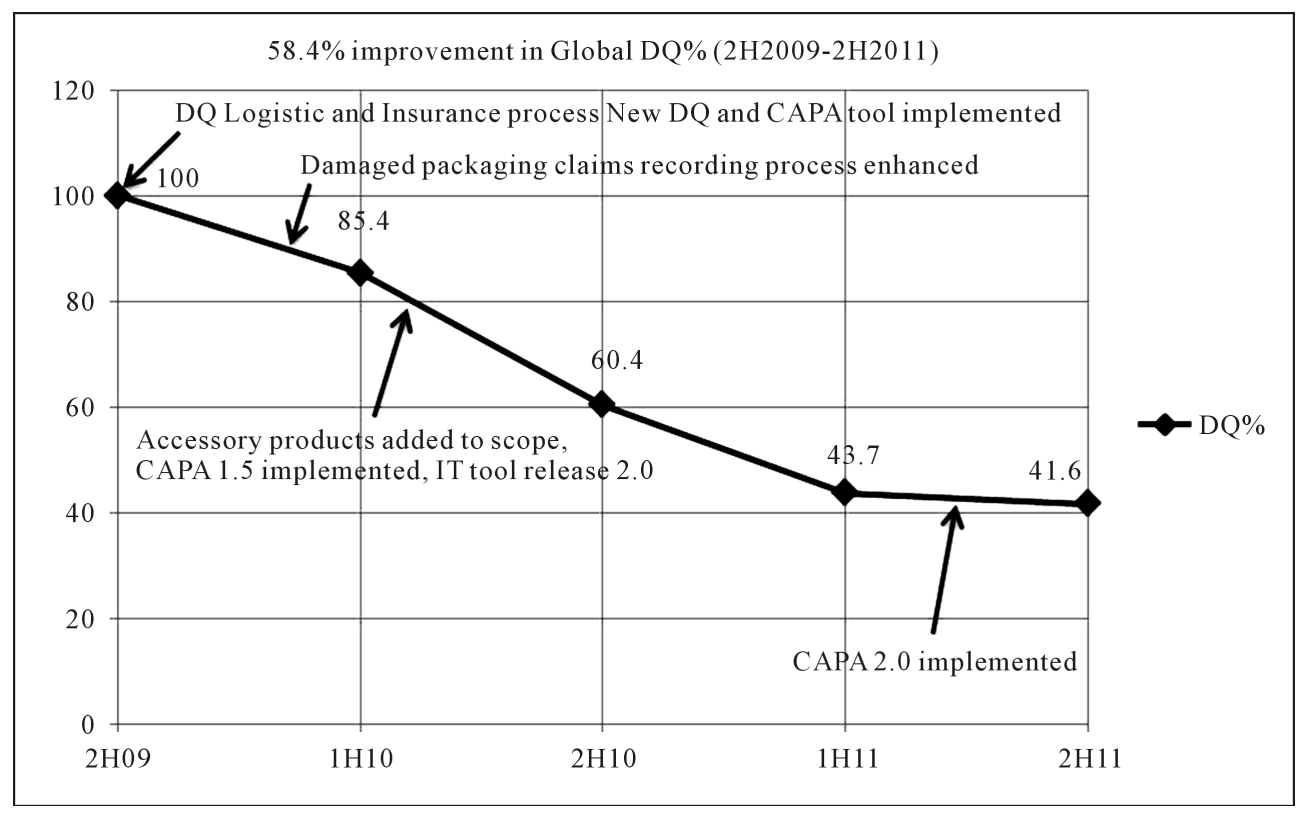

Figure 7. Global DQ\% performance results (2009-2011). 
global strategy and IT solution made it possible to improve the overall insurance claims visibility, claims management, collect the needed information more efficiently, and proceed more timely and accurately. This had a significant positive impact on Nokia's insurance claims payment values and insurance claims recoveries.

During years 2009-2012, the quantity of insurance claims remained stable, but the actual claims payment value dropped significantly (Figure 8, presented in six month periods). The insurance actual payment value improved over 76.5 percent and recoveries from LSPs improved over 10 percent since starting to utilize the global DQ claims management process and IT solution. These results validate Hypothesis H1. In Figure 8: Actual payment value (\%) is insurance payments to trade customers. Recovery (\%) is insurance recoveries received from LSPs. Target is received recoveries from LSPs defrays insurance payments to trade customers caused by LSPs.

\subsection{New DQ Change Model}

Improved DQ governance and leadership management approach enabled accurate DQ transparency for all parties throughout the entire supply chain. Improvements in management system created a joint vision and set precise DQ targets, which were possible to achieve by following the agreed processes and practices. Clearly defined roles and responsibilities and open and honest communication flow were important elements to build the DQ community. A significant success factor in DQ was a strong and effective network to drive the needed DQ and CAPA changes across the various organizations and stakeholders. Based on our observation, frequent and clear dialogue among the supply chain community increased trust across the distributed teams. Figure 9 shows the new DQ change model, which was created based on our DQ analysis. Compared to the initial approach (see Figure 4), the new change model included more evolutionary elements to achieve sustainable quality and customer-centric culture throughout the global DQ operation and stakeholders. We identified total of 12 change steps that correspond and complement with Kotter's change model (see Figure 3). The new change management model (Figure 9) included the same three main phases as the initial approach: 1) starting the change; 2) implementing the change; and 3) sustaining the change. Compared to the initial change model and Kotter's eight steps change model, the new DQ change model included more operational level elements.

The new model focused on fact-based analysis when identifying the change need. Based on the identified need, the future state vision was defined in detail level. The new approach ensured that the top management's commitment and support existed and the needed governance structure and management system were established. To achieve the needed commitment and buy-in, the communication focused on providing a consistent and meaningful targets, where 20 percent of the communication focused on "What" and 80 percent on "Why and How" aspects. Active and participative leadership was emphasized. Changing the work values and practices (in this case customer-centric operation and culture of quality) were clearly expressed. The teams were empowered globally and clear roles and responsibilities were defined. It was important to align the global teams and reward the new working culture to achieve the change. Especially, peer cooperation and employee ownership of issues

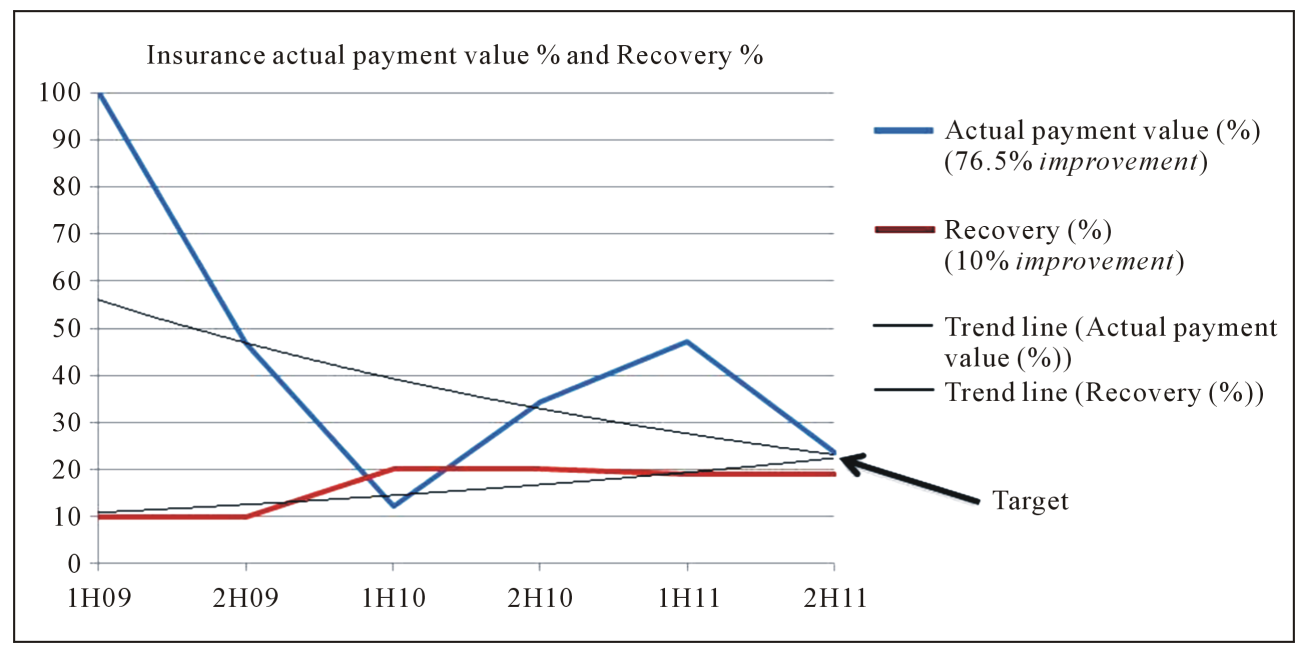

Figure 8. Insurance claims performance development. 


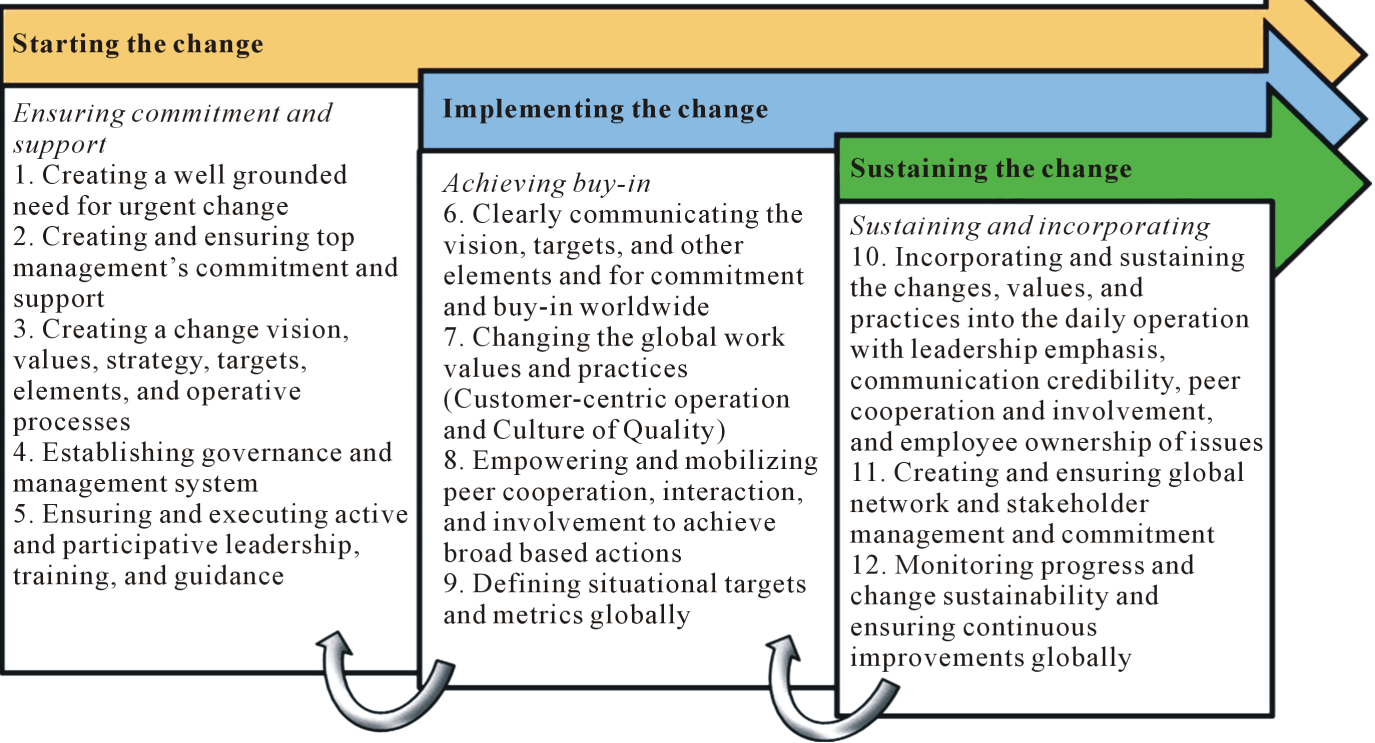

Figure 9. The evolutionary DQ change model.

were stressed. The operational level situational targets and metrics were introduced and global DQ network and stakeholder management were included. The overall change was endured by incorporating the quality and customer-centric ideology into the operational level processes and practices. It was also recognized that change as a process may not be linear, and therefore, the new change model allowed adjusting previous steps.

\section{Conclusions and Limitations}

DQ is a critical distinctive sign for company's quality perception by its customers. We identified that successful DQ practices and quality and customer-centric operation management require a cooperative stakeholder approach across the entire supply chain. Strong and ethical DQ leadership is required to drive the proper use of processes and tools to achieve the change, strategy, goals, and customer requirements. We also suggested that active and participative leadership is critical for success to avoid concentrating solely on process replacements and improvements, or letting IT system development dictate policy. We found that the main focus should be on leadership, networking, understanding the situation in the field, and nurturing relationships with customers. If management, leadership, operative practices, decision making, and escalations are inadequate, people ignore processes and practices. DQ management requires dedicated people to operate it.

We identified that selecting a contradictory strategy can bring new possibilities. Nokia's unique global DQ strategy includes product, logistics, and insurance management under the same process and IT solution. This strategy and solution improved trade customers' perception knowledge and transparency, and made it possible to improve the overall DQ performance. The globally integrated DQ strategy enabled the efficient control of all claims-related information, and managed all claims timely and thoroughly. It would be worthwhile investigating how the DQ strategy and results impact on top management's and personnel's views and operation about DQ over time.

Naturally, we acknowledge that this study has some limitations. The data and examples are from only one company and its global operation in those specific circumstances. This may limit some of the results generalization, and therefore, further research from different companies and industry fields are needed to validate and elaborate the findings. Another issue, which may require further research, is the role of outside organizations in DQ implementation projects, such as: customers, insurance company, and logistics service providers acting as facilitators and analyzing the challenge from their vantage point. Such a study would contribute to our understanding how DQ practices can be adopted within the end-to-end supply chain. Nevertheless, the DQ elements and solutions and the evolutionary DQ change model provide a tool and a frame for DQ strategy development and implementation, which can be adopted by other companies for their DQ change management activities and the 
operations while defining the required operative activities. This research could serve as a basis for the development of DQ strategy and measurement systems for assessing the success of the end-to-end supply chain delivery quality.

\section{References}

[1] Gartner (2013) The AMR Research Supply Chain Top 25. https://www.gartner.com/doc/1340552?ref=SiteSearch\&sthkw=supply\%20chain\%20top\%2025\%20for\%202007\&fnl= $\underline{\text { search }}$

[2] Muffato, M. and Panizzolo, R. (1995) A Process Based View for Customer Satisfaction. International Journal of Quality and Reliability Management, 12, 154-169. http://dx.doi.org/10.1108/02656719510101259

[3] Jablonski, J. (1992) Implementing TQM; Competing in the Nineties through Total Quality Management. 2nd Edition, San Diego, Pfeiffer.

[4] Garvin, D. (1984) What Does “Product Quality” Really Mean? Sloan Management Review, Fall, 25-45.

[5] Chang, G. (2009) Total Quality Management in Supply Chain. International Business Research, 2, 82-85.

[6] Lee, Y. and Kincade, D.H. (2003) US Apparel Manufacturers' Company Characteristic Differences Based on SCM Activities. Journal of Fashion Marketing and Management, 7, 31-48. http://dx.doi.org/10.1108/13612020310464359

[7] Power, C.A. (1999) Value and Supply Chain Management. Supply Chain Management: An International Journal, 4, 167-175.

[8] Tan, K.C, Lyman, S.B and Wisner, J.D. (2002) Supply Chain Management: A Strategic Perspective. International Journal of Operations \& Production Management, 22, 614-631. http://dx.doi.org/10.1108/01443570210427659

[9] Lockamy III, A. and McCormack, K. (2004) Linking SCOR Planning Practices to Supply Chain Performance: An Exploratory Study. International Journal of Operations \& Production Management, 24, 1192-1218. http://dx.doi.org/10.1108/01443570410569010

[10] Mills, J., Schmitz, J. and Frizelle, G. (2004) A Strategic Review of Supply Networks. International Journal of Operations \& Production Management, 24, 1012-1036. http://dx.doi.org/10.1108/01443570410558058

[11] Talib, F., Rahman, Z. and Qureshi, M.N. (2011) A Study of Total Quality Management and Supply Chain Management Practices. International Journal of Productivity and Performance Management, 60, 268-288. http://dx.doi.org/10.1108/17410401111111998

[12] Skorna, A. and Fleisch, E. (2012) Loss Prevention in Transportation to Ensure Product Quality: Insights from the Cargo Insurance Sector. In: Frick, J. and Laugen, B.T., Eds., Advances in Production Management Systems. Value Networks: Innovation, Technologies, and Management, Springer, Berlin, 148-156.

[13] Peleg-Gillai, B., Gauri, B. and Sept, L. (2006) Innovators in Supply Chain Security: Better Security Drives Business Value. Manufacturing Institute, Washington DC.

[14] Wallenius, H. (1984) Lastivahinkojen torjunta. Merikapteenityö. Kotkanmerenkulkuopisto.

[15] Jüttner, U. (2005) Supply Chain Risk Management: Understanding the Business Requirements from a Practitioner Perspective. International Journal of Logistics Management, 16, 120-141. http://dx.doi.org/10.1108/09574090510617385

[16] Peverett, E. (1993) Fire Insurance Laws and Claims. Chartered Institute of Loss Adjusters, London.

[17] Marine Insurance Act (1993) http://www.admiraltylaw.com/statutes/Marine\%20Insurance\%20Act.htm

[18] Lloyd's (2009)

http://www.lloyds.com/ /media/Files/The\%20Market/Tools\%20and\%20resources/Agency/Links\%20to\%20documents \%20from\%20LA\%20Website/Cargo\%20Claims\%20\%20Recoveries_module\%203.pdf

[19] ICC: International Chamber of Commerce. http://www.iccwbo.org/products-and-services/trade-facilitation/incoterms-2010/

[20] ICC (2000) International Chamber of Commerce, Incoterms 2000, ICC Official Rules for the Interpretation of Trade Terms, ICC Publication No. 560. ICC Publishing S.A., Paris.

[21] Skorna, A.C., Bode, C. and Wagner, S.M. (2009) Technology-Enabled Risk Management along the Transport Logistics Chain. In: Wagner, S.M. and Bode, C., Eds., Managing Risk and Security, Haupt, Berne, 197-220.

[22] Kotter, J. (1996) Leading Change. Harvard Business Review Press, Boston.

[23] Geoghegan, J. and Farrington, A. (1995) Shared Governance: Developing a British Model. British Journal of Nursing, 4, 780-783.

[24] Scott, L. and Caress, A. (2005) Shared Governance and Shared Leadership: Meeting the Challenges of Implementation. Journal of Nursing Management, 13, 4-12. http://dx.doi.org/10.1111/j.1365-2834.2004.00455.x 
[25] Edmonstone, J. (1998) Making Shared Governance Work. Nursing Management, 5, 7-9.

[26] Carmignani, G. (2009) Supply Chain and Quality Management: The Definition of a Standard to Implement a Process Management System in a Supply Chain. Business Process Management Journal, 15, 395-407. http://dx.doi.org/10.1108/14637150910960639

[27] ISO 9001 (2008) Quality Management Principles. http://www.iso.org/iso/qmp_2012.pdf

[28] Cyr, D. (1999) High Tech, High Impact: Creating Canada’s Competitive Advantage through Technology Alliances. Academy of Management Executive, 13, 17-28.

[29] Nissinen, V. (2006) Deep Leadership. Talentum, Helsinki.

[30] Welikala, D. and Sohal, A. (2008) Total Quality Management and Employees’ Involvement: A Case Study of an Australian Organization. Total Quality Management \& Business Excellence, 19, 627-642. http://dx.doi.org/10.1080/14783360802024440

[31] Sun, H., Hui, I., Tam, A. and Frick, J. (2000) Employee Involvement and Quality Management. TQM Magazine, 12, 350-354. http://dx.doi.org/10.1108/09544780010341969

[32] Wilkinson, A. (1998) Empowerment: Theory and Practice. Personnel Review, 27, 40-56. http://dx.doi.org/10.1108/00483489810368549

[33] Dale, B., Cooper, C. and Wilkinson, A. (1997) Managing Quality and Human Resources: A Guide to Continuous Improvement. 2nd Edition, Blackwell Publishers, Oxford.

[34] Fawcett, S., Magnan, G. and McCarter, M. (2008) Benefits, Barriers, and Bridges to Effective Supply Chain Management. Supply Chain Management: An International Journal, 13, 35-48. http://dx.doi.org/10.1108/13598540810850300

[35] Deming, W.E. (1950) Elementary Principles of the Statistical Control of Quality. JUSE.

[36] Linderman, K., Schroeder, R., Zahees, S. and Choo, A. (2003) Six Sigma: A Goal-Theoretic Perspective. Journal of Operations Management, 21, 193-203. http://dx.doi.org/10.1016/S0272-6963(02)00087-6

[37] Kwak, Y.H. and Anbari, F.T. (2006) Benefits, Obstacles, and Future of Six Sigma Approach. Technovation, 26, 708715. http://dx.doi.org/10.1016/j.technovation.2004.10.003

[38] Harrington, H.J. and Mathers, D.D. (1997) ISO 9000 and Beyond: From Compliance to Performance Improvement. McGraw-Hill, New York.

[39] Cole, R.E. (1998) Learning from the Quality Movement: What Did and Didn’t Happen and Why? California Management Review, 41, 43-73. http://dx.doi.org/10.2307/41165975

[40] Näslund, D. (2002) Logistics Needs Qualitative Research—Especially Action Research. International Journal of Physical Distribution \& Logistics Management, 32, 321-338. http://dx.doi.org/10.1108/09600030210434143

[41] Checkland, P. (1993) Systems Thinking, Systems Practice. John Wiley \& Sons, New York.

[42] McNiff, J. and Whitehead, J. (2000) Action Research in Organisations. Routledge, London.

[43] Reason, P. and Bradbury, H. (2001) Introduction: Inquiry and Participation in Search of a World Worthy of Human Aspiration. In: Reason, P. and Bradbury, H., Eds., Handbook of Action Research, Sage, London, 1-14.

[44] Susman, G. (1983) Action Research: A Sociotechnical Systems Perspective. In: Morgan, G., Ed., Beyond Method: Strategies for Social Research, Sage, Newbury Park, 95-113.

[45] OECD (2004) The Organization for Economic Cooperation and Development-Guidelines for Good Practice for Insurance Claim Management. http://www.oecd.org/pensions/insurance/33964905.pdf 
Scientific Research Publishing (SCIRP) is one of the largest Open Access journal publishers. It is currently publishing more than 200 open access, online, peer-reviewed journals covering a wide range of academic disciplines. SCIRP serves the worldwide academic communities and contributes to the progress and application of science with its publication.

Other selected journals from SCIRP are listed as below. Submit your manuscript to us via either submit@scirp.org or Online Submission Portal.
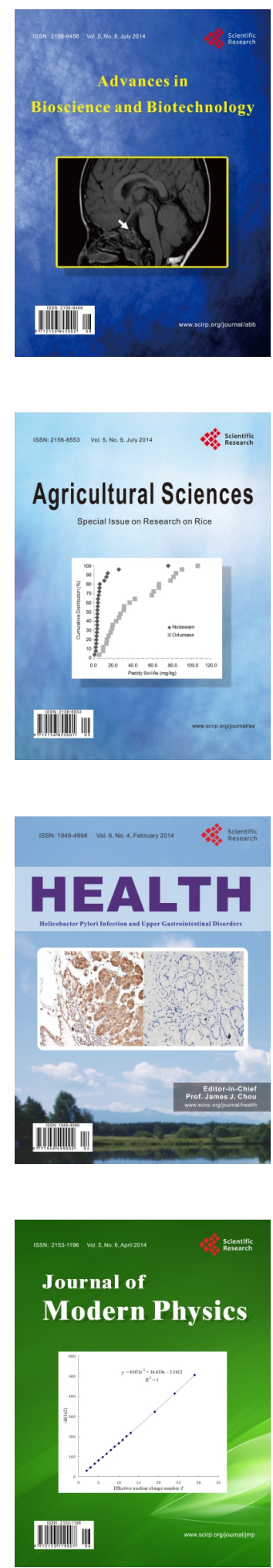
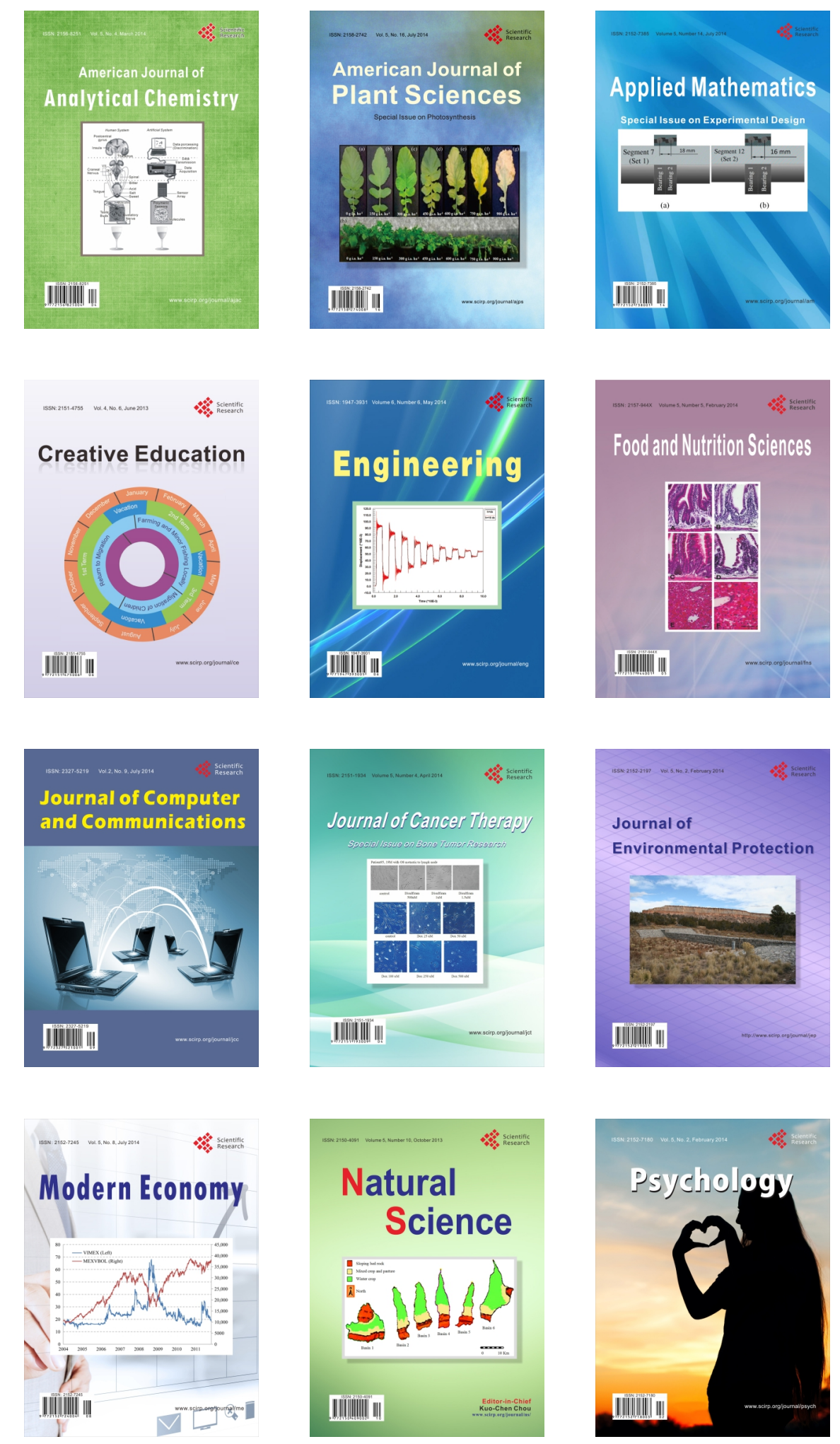